\title{
Psychopathological Symptoms, Social Skills, and Personality Traits: A Study with Adolescents
}

\author{
Maite Garaigordobil Landazabal \\ Universidad del País Vasco
}

\begin{abstract}
The purpose of this study is two-fold: (a) to study the concomitant relationships between psychopathological symptoms, cooperation, social skills, and other personality traits; and (b) to identify the predictive variables of psychopathological symptoms. The sample consists of 322 adolescents aged 14 to 17 years old. This study uses correlational methodology. In order to assess psychopathological symptoms, cooperation, social skills, and personality traits, the following scales are used: the Symptom Checklist (SCL-90-R; Derogatis, 1983), the Cooperativeness Scale (CS; Rigby, Cox, \& Black, 1997), the MESSY social skills scale (Matson, Rotatori, \& Helsel, 1983), and the TPT Personality Test (Corral, Pamos, Pereña, \& Seisdedos, 2002). Pearson coefficients suggest that adolescents with many psychopathological symptoms have low levels of cooperative behaviors and social skills. They also score high in inappropriate assertiveness, impulsiveness, overconfidence, and jealousy-withdrawal and have low levels of emotional stability, sociability, and responsibility. Through multiple regression analyses, the following variables were identified as predictors of psychopathological symptoms: jealousy-withdrawal, low social integration, impulsiveness, and low self-concept. The role played by intervention programs promoting socio-emotional development to prevent psychopathological symptoms and enhance mental health is discussed.

Keywords: psychopathological symptoms, social behaviors, personality, adolescence
\end{abstract}

\begin{abstract}
El estudio tiene 2 objetivos: 1) analizar las relaciones de los síntomas psicopatológicos con cooperación, habilidades sociales, y otros rasgos de personalidad; y 2) identificar variables predictoras de síntomas psicopatológicos. La muestra está constituida por 322 adolescentes de 14 a 17 años. El estudio utiliza una metodología correlacional. Los síntomas psicopatológicos, la capacidad de cooperación, las habilidades sociales y diversos rasgos de personalidad fueron medidos con 4 instrumentos de evaluación: el cuestionario SCL-90-R (Derogatis, 1983), la escala de cooperación (EC; Rigby, Cox y Black, 1997, la escala de habilidades sociales MESSY (Matson, Rotatori y Helsel, 1983), y el test de personalidad TPT (Corral, Pamos, Pereña y Seisdedos, 2002). Los coeficientes de Pearson sugieren que los adolescentes con muchos síntomas psicopatológicos tienen pocas conductas de cooperación, pocas habilidades sociales, mucha asertividad inapropiada, impulsividad, sobrevaloración, y celos-soledad, así como baja estabilidad emocional, sociabilidad y responsabilidad. El análisis de regresión múltiple permite identificar 4 variables predictoras de síntomas psicopatológicos: alto nivel de celos-soledad, baja integración social, impulsividad y bajo autoconcepto. La discusión plantea el papel que pueden tener los programas de intervención socio-emocional durante la infancia para prevenir la emergencia de síntomas psicopatológicos y para fomentar la salud mental.
\end{abstract}

Palabras clave: síntomas psicopatológicos, conductas sociales, personalidad, adolescencia

This work was financed by the Vicerrectorado de Investigación de la Universidad del País Vasco (1/UPV 00006.231-H-15910/2004). Correspondence concerning this article should be addressed to Maite Garaigordobil, Facultad de Psicología, Universidad del País Vasco, Avenida de Tolosa 70, 20018 San Sebastián (Spain). Phone: 943-015936. Fax: 943-015670. E-mail: maite.garaigordobil@ehu.es Translation: Virginia Navascués Howard 
In the last few years, research to identify protecting factors for the development of psychopathological symptoms has become increasingly important. In order to avoid psychopathological problems in adolescence, the relevant developmental variables must be identified so we can establish preventive programs to apply during childhood. From this perspective, the purpose of this study is to identify social behaviors and personality traits associated with psychopathology, and that may have a preventive effect on the development of psychopathological symptoms in adolescence.

The works, based mainly on theoretical personological frameworks, which have analyzed the relations between psychopathological symptoms, social behaviors, and personality traits, underscore the existence of positive correlations between mental health and self-concept, indicating that people with many psychopathological symptoms have low self-concept/self-esteem (Erol, Toprak, \& Yazici, 2002; Fan \& Fu, 2001; Montt \& Chavez, 1996; Watson, 1998). Moreover, the importance of social integration for mental health has also been suggested (Wilmoth \& Chen, 2003), pointing to difficulties in social relations as predictors of psychopathological symptoms (Richter, 1999).

Some studies have found negative relations between psychosomatic symptoms and self-concept (Dowd, 2002; Garrick, Ostrov, \& Offer, 1988) and sociability (Watten, Vassend, Myhrer, \& Syversen, 1997). No significant correlations have been found between somatization and stress tolerance (Norman, 2002), and cooperation (Watten et al.). Other works reported high obsessive-compulsive tendencies to be related with low self-esteem (Biby, 1998), in fact, with low self-esteem being a strong predictor of obsessivecompulsive personality disorder (Watson, 1998). Some investigators have found a negative relation between interpersonal sensitivity and self-esteem (Fan \& Fu, 2001; Jackson \& Cochran, 1991; Kim, 2003), identifying interpersonal sensitivity in women as a risk factor for depression and other psychiatric disorders (Giardinelli, Paionni, Zucchi, Viviani, \& Cabras, 1999).

Negative correlations have also been found between depression and self-concept/self-esteem (Alfeld \& Sigelman, 1998; Biby, 1998; Bohne, Keuthen, Wilhelm, Deckersback, \& Jenike, 2002; Erkolahti, Ilonen, Saarijarvi, \& Terho, 2003; Fan \& Fu, 2001; Hoffmann, Baldwin, \& Cerbone, 2003; Kim, 2003; Sakamoto, Tomoda, \& Kijima, 2002; Valentine, 2001), with high self-esteem being a protective factor against depressive symptoms (Takakura \& Sakihara, 2001) and low self-esteem a predictor of attempted suicide (Jin \& Zhang, 1998). Among the factors that have been identified as predictors of depression are trait-anxiety (Bromberger \& Matthews, 1996) and low frustration tolerance (Chang \& D'Zurilla, 1996). The results of the study of Ramos and Wilmoth (2003) show that social integration decreases depressive symptoms, and the work of Roland (2002) underlined the negative relations between depression and violent behavior, but only in girls.

In contrast, some investigations confirm inverse relations between anxiety and self-concept/self-esteem. These works suggest that adolescents with low levels of state-trait anxiety have high self-esteem (Bohne et al., 2002; Fickova, 1999; Garaigordobil, Cruz, \& Pérez, 2003; Newbegin \& Owens, 1996; Yang, 2002), and they have identified low frustration tolerance as a predictor of anxiety symptoms (Chang \& D'Zurilla, 1996). Other studies have found negative correlations between self-concept/self-esteem and hostilityaggressiveness (Allison, 2000; Marsh, Parada, Yeung, \& Healey, 2001; O'Moore \& Kirkham, 2001; Rigby \& Slee, 1993; Rozenblatt, 2002), paranoid ideation (Ellett, Lopes, \& Chadwick, 2003; Martin \& Penn, 2001), and psychoticism (Fan \& Fu, 2001).

Recrently, Malouff, Thorsteinsson, and Schutte (2005) carried out a meta-analysis of 33 studies that examined the relations between the Big Five model and symptoms of clinical disorders. The pattern found associated high neuroticism, low conscientiousness, low agreeableness, and low extraversion with clinical disorders. Comparisons of diagnostic and norm groups showed higher levels of Neuroticism and lower levels of Extraversion than did studies of correlations between measures of the level of a disorder and measures of the Big Five. Studies of observer ratings of the Big Five showed lower levels of Neuroticism and Openness than did studies using self-report ratings. The results of this meta-analysis underscore the effect of the methodology and the techniques used on the relations that are found between personality factors and psychopathological symptoms.

This study is based on a psychometric, personological framework, and in the current reformulation, the interactionist viewpoint (Person $\times$ Environment) is taken into account. Taking as reference point the above-mentioned works, the investigation has two aims. The first goal is to analyze the relations of various psychopathological symptoms with adolescents' capacity to cooperate, with their social skills and with four important personality dimensions (emotional stability, mental openness, sociability, and responsability). The second goal of the study consists of identifying social behaviors and personality traits that may be predictors of psychopathological symptoms. The work was carried out with adolescents because adolescence is a stage of instability, a critical phase in the life span, susceptible to the development of psychopathological symptoms, and an important moment in the configuration process of the definite personality.

In this investigation, seven hypotheses were proposed:

1. Psychopathological symptoms will have a significant and negative relation with the capacity of cooperation.

2. There will be a significant negative relation between psychopathological symptoms and social skills, as well as a positive correlation with inappropriate assertiveness, impulsiveness, overconfidence, and jealousy-withdrawal. 
3. Psychopathological symptoms will have a significant negative relation with emotional stability.

4. Significant negative correlations will be found between psychopathological symptoms and mental openness.

5. Psychopathological symptoms will have a negative correlation with sociability.

6. There will be a significant negative relation between psychopathological symptoms and responsability.

7. Low levels of sociability will predict psychopathological symptoms.

\section{Method}

\section{Participants}

The sample was made up of 322 adolescents, ages 14 to 17 years old. Mean sample age was 14.78 years $(S D=$ 0.86): $42.8 \%(n=138)$ were 14 years old, $32.9 \%(n=106)$ were 15 years old, $14.6 \%(n=47)$ were 16 years old, $4 \%$ $(n=13)$ were 17 years old, and 5.6\% $(n=18)$ did not report their age. The entire sample of participants was distributed in 16 groups, registered in four school centers of the province of Guipúzcoa (Spain). Nine groups ( $\mathrm{n}=193$ individuals) were in their $3^{\text {rd }}$ year of Compulsory Secondary Education, and 7 groups ( $n=129$ students) were in their $4^{\text {th }}$ course. Of the sample, $53.4 \%$ were males $(n=172), 45.3 \%(n=146)$ were females, and $1.2 \%(n=4)$ did not report their sex. One hundred and ten $(34.2 \%)$ were students at a public educational center and $212(65.8 \%)$ were in private centers. With regard to their socio-economic and cultural level, they were asked to report both their parents' educational levels. Almost one fourth of the sample reported that the father had studied up to the age of 14 years $(23 \%)$, or else were college graduates $(23.9 \%)$, and almost one fourth of the mothers had a diploma $(23.9 \%)$ or else were college graduates $(20.5 \%)$. Most of the fathers $(90.4 \%)$ and mothers $(80.4 \%)$ were working.

Simple probabilistic random sampling was used: the sample was randomly selected from the educational centers of Secondary Education of the province of Guipúzcoa, taking into account both public and private centers of rural and urban areas. All the educational centers of the province were listed and four of them were selected randomly. In these centers, there were 16 groups or classrooms, 8 for each course ( $3^{\text {rd }}$ and $4^{\text {th }}$ grade of Compulsory Secondary Education). All the groups of each center were assessed, that is, four groups in each center, two from each educational level.

\section{Instruments}

Four assessment instruments with psychometric guarantees were used to measure the following variables: psychopathological symptoms, capacity of cooperation, social skills, and personality traits.
SCL-90-R. Symptom Checklist-90-Revised (Derogatis, 1983). This self-report is made up of 90 items, distributed in 10 scales that provide information about psychopathological alterations: (a) Somatization (12 neurovegetative symptoms); (b) Obsessive-Compulsive (10 symptoms); (c) Interpersonal Sensitivity (9 symptoms that describe feelings of bashfulness and shame, a tendency to feel inferior to others, hypersensitivity to others' opinions and attitudes and, in general, discomfort and inhibition in interpersonal relationships); (d) Depression (13 symptoms that describe clinical signs and symptoms of depressive disorders); (e) Anxiety (10 symptoms referring to the clinical manifestations of anxiety, both generalized and acute); (f) Hostility (6 symptoms referring to thoughts, feelings, and behaviors that are characteristic of states of aggressiveness, anger, irritability, rage, or resentment); (g) Phobic Anxiety (7 symptoms that assess variants of phobic experience); (h) Paranoid Ideation (6 symptoms of paranoid behavior, considered mainly a thought disorder that includes suspiciousness, self-referential centralism and delusional ideation, hostility, grandiosity, fear of losing autonomy, and need to control); (i) Psychoticism (10 symptoms that make up a psychotic spectrum that goes from slight schizoidia to full-fledged psychosis, and which in the general population is more related to feelings of social alienation than with clinically manifest psychosis); and an (j) Additional Scale (7 miscellaneous symptoms that are a clear reference to melancholic depression).

A Total Symptom Score in the SCL-90-R is obtained by adding the scores in the 10 scales. Moreover, the test provides a Global Severity Index, a generalized and indiscriminate measure of the intensity of psychological and global psychosomatic suffering; a Positive Symptom Total, the number of symptoms present; and a Positive Symptom Distress Index, which relates the suffering or global distress to the number of symptoms. Examples of items of each scale are: "feeling weak in some part of your body" (somatization), "having to check over and over everything you do" (obsessive-compulsive), "being too sensitive or feeling hurt easily" (interpersonal sensitivity), "feeling trapped or locked up" (depression), "the feeling that something bad is going to happen" (anxiety), "getting annoyed, irritated, or angry easily" (hostility), "having to avoid certain things, places, or activities because you are afraid of them" (phobic anxiety), "feeling that other people stare at you or talk about you" (paranoid ideation), "the idea that another person controls your thoughts" (psychoticism), and "uneasy or troubled sleep" (additional). Results from studies conducted with a Spanish sample (González de Rivera, De las Cuevas, Rodríguez Abuín, \& Rodríguez Pulido, 2002) obtained satisfactory reliability and were consistent with those carried out by Derogatis. The values of the alpha coefficients ranged between .81 and .90 . Internal consistency coefficients indicate that item homogeneity of each dimension is very high. Temporal stability (between 
.78 and .90$)$ with a 1-week test-retest interval showed score stability over that period. Another study by González de Rivera, De la Hoz, Rodríguez Abuín, \& Monterrey (1999) also revealed the relation between the profile of symptomatic dimensions and the diagnostic group of the clinical sample (obtaining significantly higher scores in psychiatric samples than in nonclinical samples), thus reinforcing the validity of the instrument. The authors' original studies with American samples showed construct validity (Derogatis \& Cleary, 1977) and convergent validity, in view of the high correlations of the symptomatic dimensions with the MMPI in psychiatric patients (Derogatis, Rickels, \& Rock, 1976), as well as criterion or empirical validity (Derogatis).

Cooperativeness Scale (CS; Rigby, Cox, \& Black, 1997). This 18 -item scale measures the individual's capacity to cooperate with others, defining cooperation as behaving conjointly and coordinately at work, leisure, or in social relationships, for the pleasure of sharing activities, goals, or simply to enhance relationships. Participants rate their responses on a 5-point Likert scale, ranging from 1 (totally disagree) to 5 (totally agree). Of the 18 items of the test, 9 reflect cooperative attitudes and 9 uncooperative attitudes. Item examples are: "team work is the best way to get results" (cooperative attitudes) and "it is more productive to work alone" (uncooperative attitudes). In the authors' study, conducted in Australia with a sample of adolescents, adequate reliability was obtained (Cronbach's $\alpha=.79$ ). In this same study, concurrent validity was examined in a sample of students, controlling age and obtaining correlations with other measures. The results showed that the correlation of cooperation with the number of friends was low $(r<.20)$, and the quality of friendships was a better indicator of cooperation than the number of friends, thus confirming a significant link between cooperation and happiness.

The Matson Evaluation of Social Skills in Youngsters (MESSY; Matson, Rotatori, \& Helsel, 1983). The Spanish adaptation was used (Trianes et al., 2002). This instrument is made up of 62 items, with response options rated on a 4-point Likert scale ranging from 1 (never) to 4 (always). The scale evaluates five factors: (a) Appropriate Social Skills (behaviors such as emotional expressiveness, having friends, sharing); (b) Inappropriate Assertiveness (aggressive behaviors, making fun of or abusing others); (c) Impulsiveness (behaviors such as getting angry easily or interrupting others); (d) Overconfidence (overvaluing oneself); and (e) Jealousy-Withdrawal (feelings of loneliness, lack of friends). Item examples of each scale are: "I know how to make friends" (social skills), "I get back at people who offend me" (inappropriate assertiveness), "I interrupt others when they are talking" (impulsiveness), "I like to brag about the things I have" (overconfidence), and "I feel jealous of others" (jealousy/withdrawal). A study (Méndez, Hidalgo, \& Inglés, 2002) carried out with the Spanish version of the MESSY in a sample of 634 adolescents of ages 12 to 17 showed high internal consistency (Cronbach's $\alpha=$
.88). In this study, Pearson correlation coefficients were calculated between the total MESSY score and other measures of assertiveness and social skills. Inappropriate social behaviors had negative correlations with assertiveness, prosocial, and submissive behavior, and positive correlations with aggressiveness and asocial behavior.

TEA Personality Test (TPT; Corral, Pamos, Pereña, \& Seisdedos, 2002). This test evaluates 15 personality traits grouped into four dimensions: (a) Emotional Stability, which has 5 traits related to emotional maladjustment (maladjustment associated with instability, getting upset easily when coping with demands of the milieu and its emotions; anxiety related to tension, over-arousal, worry; depression linked to worries, irrational beliefs, poor selfconcept; stress tolerance associated with difficulties coping with tense situations; and self-concept, which reflects individuals' self-appraisal of their possibilities); (b) Mental Openness, related to adaptation to the environment, and includes 4 personality traits (tolerance and flexibility towards various situations; adaptation to change or to novel situations; interest in other cultures, in relation to learning about them in detail; and disposition towards new tasks); (c) Sociability, which includes 3 traits (social intelligence to establish appropriate relations with others; social integration based on respect and acceptance of rules and social traditions; and teamwork defined in terms of participation and collaboration); and (d) Responsibility, which includes 3 traits (professional self-demandingness, which evaluates professional motivation and ambition; dynamism or energy to work; and tenacity-constancy, which evaluates the capacity to persevere in a task, even under adverse conditions). The TPT is inspired in the Big Five model and allows us to explore four big personality factors. Respondents are requested to report whether the item content can be selfapplied "almost never, sometimes, frequently, or almost always". Scores range from 0-3 for "positive" items and are reversed for "negative" ones. Several studies were performed by the authors with three samples to analyze reliability. The first study collected data from one of the first experimental groups, the second one included all the existing cases, and the third study was made up of university candidates in a selection process. The alpha coefficients range between .40 and .80. These indexes are sufficiently high for questionnairetype personality tests that have scales with few elements (10 per scale).

\section{Design and Procedure}

This study employed correlational methodology to establish relations of concomitance between psychopathological symptoms, the capacity to cooperate, social skills, and four important personality dimensions. Step-wise linear multiple regression analysis was also conducted to determine the variables that predict psychopathological symptoms. For all analyses, the computer program SPSS 13.0 was used. 
The four assessment instruments described above were administered to the participants in two 1-hour sessions. In the first session, the SCL-90 and the CS were administered, and in the second session, the TPT and the MESSY. The tests were administered by the school center psychologists in collaboration with postgraduate students. All participants were informed about the goals of the work, the confidentiality and anonymity of their participation, and its voluntary nature, and informed consent was obtained.

\section{Results}

\section{Relations between Psychopathological Symptoms, Cooperation, and Social Skills}

To explore the relations among psychopathology, cooperation, and social skills, Pearson correlation coefficients among the scores obtained in the SCL-90-R, the CS, and the MESSY were calculated. The results can be seen in Table 1 .

An overview of the results in Table 1 suggests that the adolescents who had few psychopathological symptoms (Total Symptom Scales of the SCL-90-R) displayed high levels of cooperation, adequate social skills, and low levels of inappropriate assertiveness, impulsiveness, overconfidence, and jealousy-withdrawal.

When analyzing each specific variable, the significant negative correlations between the capacity of cooperation and all the psychopathological symptoms except for somatization and the Positive Symptom Distress Index were confirmed (see Table 1). These results indicate that adolescents with many cooperative behaviors had few of the psychopathological symptoms studied herein. In general, they had low Total Symptom Scores, low Global Severity Indexes, and low Positive Symptom Totals.

As seen in Table 1, social skills had negative correlations with many psychopathological symptoms (especially interpersonal sensitivity, phobic anxiety, and psychoticism). This indicates that adolescents with good social skills experienced very few of these symptoms and they had low Total Symptom Scores, low Global Severity Indexes, and low Positive Symptom Totals.

Inappropriate assertiveness had significant positive correlations with all the psychopathological symptoms except for somatization (Table 1). These data indicate that adolescents who frequently displayed inappropriate assertiveness suffered from many of the above-mentioned psychopathological symptoms-particularly hostility, paranoid ideation, and psychoticism-and they presented high Total Symptom Scores, high Global Severity Indexes, high Positive Symptom Indexes, and high Positive Symptom Distress Indexes.

Impulsiveness and jealousy-withdrawal also had significant and positive correlations with all the psychopathological measures. This suggests that impulsive adolescents and adolescents with high levels of jealousywithdrawal also had high scores in all the psychopathological scales and in the three psychopathological indexes used.

Overconfidence presented significant positive relations with all the psychopathological scales except for the Positive Symptom Distress Index. This indicates that overconfident adolescents displayed many psychopathological symptoms from all the scales, high Total Symptom Scores, high Global Severity Indexes, and high Positive Symptom Totals.

Table 1

Pearson Correlation Coefficients among Psychopathological Symptoms, Cooperation, and Social Skills

\begin{tabular}{|c|c|c|c|c|c|c|}
\hline SCL-90-R & $\begin{array}{c}\text { CS } \\
\text { Cooperation }\end{array}$ & $\begin{array}{c}\text { MESSY } \\
\text { Social skills } \\
\text { assertiveness }\end{array}$ & $\begin{array}{c}\text { MESSY } \\
\text { Inappropriate } \\
\text { assertiveness }\end{array}$ & $\begin{array}{c}\text { MESSY } \\
\text { Impulsiveness }\end{array}$ & $\begin{array}{c}\text { MESSY } \\
\text { Overconfidence }\end{array}$ & $\begin{array}{c}\text { MESSY } \\
\text { Jealousy- } \\
\text { Withdrawa }\end{array}$ \\
\hline Somatization & -.02 & $-.13 *$ & .09 & $.31 * * *$ & $.11 *$ & $.33 * * *$ \\
\hline Obsessive-compulsive & $-.19 * * *$ & $-.12 *$ & $.18 * *$ & $.34 * * *$ & $.13 *$ & $.48 * * *$ \\
\hline Interpersonal sensitivity & $-.20 * * *$ & $-.18 * * *$ & $.23 * * *$ & $.36 * * *$ & $.16 * *$ & $.62 * * *$ \\
\hline Depression & $-.16 * *$ & -.09 & $.21 * * *$ & $.41 * * *$ & $.12 *$ & $.58 * * *$ \\
\hline Anxiety & $-.16 * *$ & $-.11 *$ & $.29 * * *$ & $.31 * * *$ & $.21 * * *$ & $.51 * * *$ \\
\hline Hostility & $-.20 * * *$ & -.08 & $.42 * * *$ & $.48 * * *$ & $.29 * * *$ & $.48 * * *$ \\
\hline Phobic anxiety & $-.28 * * *$ & $-.20 * * *$ & $.30 * * *$ & $.24 * * *$ & $.26 * * *$ & $.49 * * *$ \\
\hline Paranoid ideation & $-.16 * *$ & -.07 & $.33 * * *$ & $.39 * * *$ & $.20 * * *$ & $.58 * * *$ \\
\hline Psychoticism & $-.26 * * *$ & $-.16 * *$ & $.34 * * *$ & $.30 * * *$ & $.27 * * *$ & $.60 * * *$ \\
\hline Additional-Melancholic depression & $-.16 * *$ & -.08 & $.27 * * *$ & $.40 * * *$ & $.18 * * *$ & $.50 * * *$ \\
\hline Total Symptom Score & $-.21 * * *$ & $-.16 * *$ & $.31 * * *$ & $.44 * * *$ & $.21 * * *$ & $.65 * * *$ \\
\hline GSI - Global Severity Index & $-.20 * * *$ & $-.16 * *$ & $.30 * * *$ & $.44 * * *$ & $.20 * * *$ & $.64 * * *$ \\
\hline PST - Positive Symptom Total & $-.28 * * *$ & $-.24 * * *$ & $.34 * * *$ & $.43 * * *$ & $.24 * * *$ & $.61 * * *$ \\
\hline PSDI - Positive Symptom Distress Index & -.09 & -.02 & $.18 * *$ & $.38 * * *$ & .10 & $.49 * * *$ \\
\hline
\end{tabular}

$* p<.05 . * * p<.01 . * * * p<.001$. 


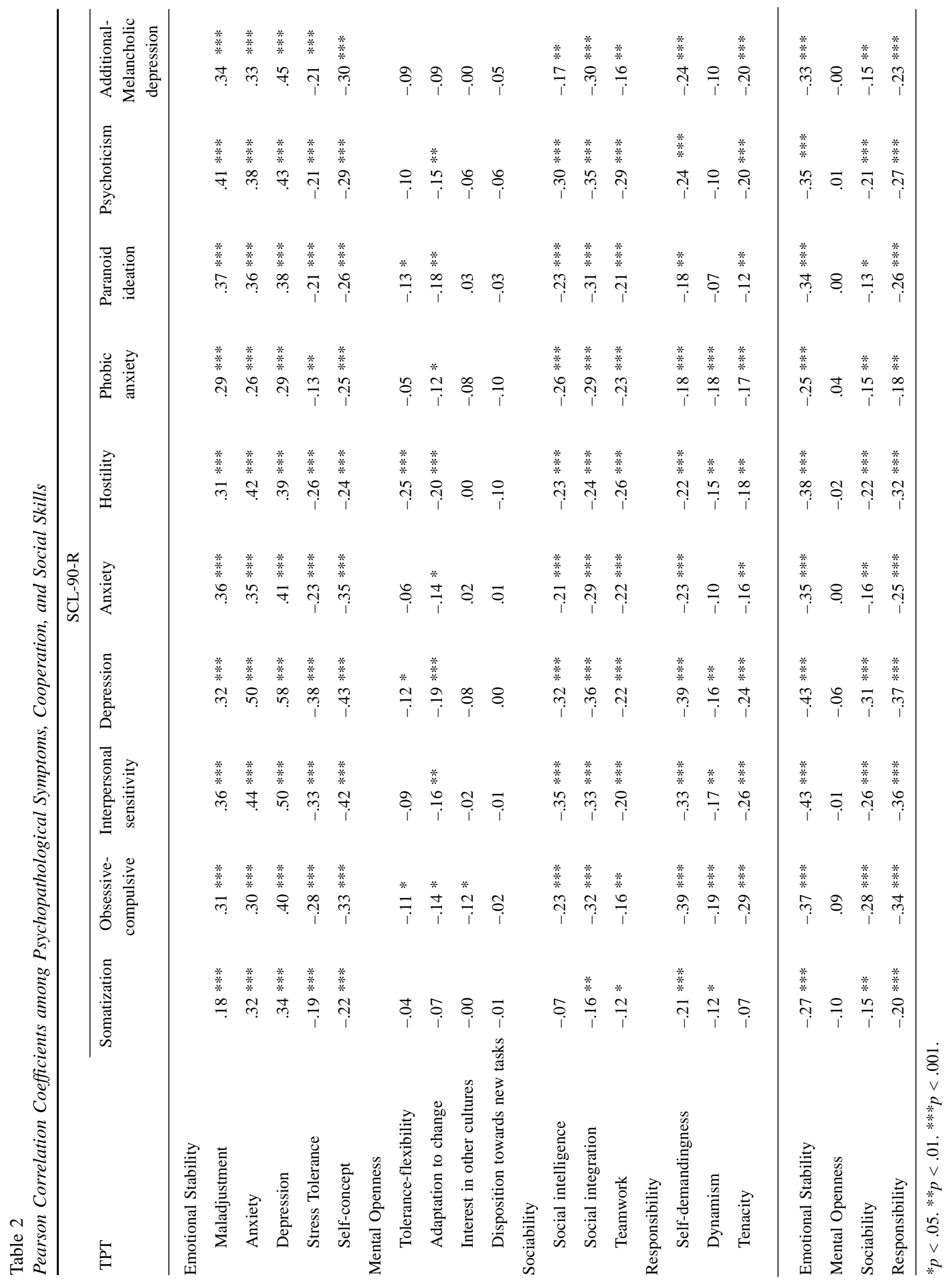


Table 3

Pearson Correlation Coefficients among Psychopathological Symptoms Psychopathological Indexes, and Personality Traits

\begin{tabular}{|c|c|c|c|c|}
\hline \multirow{2}{*}{ TPT } & \multicolumn{4}{|c|}{ SCL-90-R } \\
\hline & Total Symptom Score & GSI & PST & PSDI \\
\hline \multicolumn{5}{|l|}{ Emotional Stability } \\
\hline Maladjustment & $.38 * * *$ & $.38 * * *$ & $.39 * * *$ & $.29 * * *$ \\
\hline Anxiety & $.48 * * *$ & $.48 * * *$ & $.42 * * *$ & $.38 * * *$ \\
\hline Depression & $.55 * * *$ & $.55 * * *$ & $.49 * * *$ & $.48 * * *$ \\
\hline Stress Tolerance & $-.33 * * *$ & $-.33 * * *$ & $-.26 * * *$ & $-.33 * * *$ \\
\hline Self-Concept & $-.41 * * *$ & $-.41 * * *$ & $-.37 * * *$ & $-.37 * * *$ \\
\hline \multicolumn{5}{|l|}{ Mental Openness } \\
\hline Tolerance-flexibility & $-.16 * *$ & $-.16 * *$ & $-.15 * *$ & $-.16 * *$ \\
\hline Adaptation to change & $-.20 * * *$ & $-.20 * * *$ & $-.21 * * *$ & $-.13 *$ \\
\hline Interest in other cultures & -.05 & -.05 & -.07 & .02 \\
\hline Tolerance-flexibility & -.05 & -.05 & -.06 & .00 \\
\hline \multicolumn{5}{|l|}{ Sociability } \\
\hline Social intelligence & $-.32 * * *$ & $-.32 * * *$ & $-.33 * * *$ & $-.23 * * *$ \\
\hline Social integration & $-.39 * * *$ & $-.39 * * *$ & $-.36 * * *$ & $-.30 * * *$ \\
\hline Teamwork & $-.24 * * *$ & $-.24 * * *$ & $-.25 * * *$ & $-.17 * *$ \\
\hline \multicolumn{5}{|l|}{ Responsibility } \\
\hline Selfdemandingness & $-.36 * * *$ & $-.36 * * *$ & $-.34 * * *$ & $-.29 * * *$ \\
\hline Dynamism & $-.18 * * *$ & $-.18 * * *$ & $-.16 * * *$ & $-.15 * * *$ \\
\hline Tenacity & $-.26 * * *$ & $-.26 * * *$ & $-.22 * * *$ & $-.27 * * *$ \\
\hline Emotional Stability & $-.45 * * *$ & $-.45 * * *$ & $-.45 * * *$ & $-.39 * * *$ \\
\hline Mental Openness & -.03 & -.03 & -.02 & -.00 \\
\hline Sociability & $-.29 * * *$ & $-.29 * * *$ & $-.29 * * *$ & $-.19 * * *$ \\
\hline Responsibility & $-.38 * * *$ & $-.38 * * *$ & $-.39 * * *$ & $-.32 * * *$ \\
\hline
\end{tabular}

Note GSI = Global Severity Index; PST = Positive Symptom Total; PSDI = Positive Symptom Distress Index.

$* p<.05 . * * p<.01 . * * * p<.001$.

To sum up, the adolescents who had few psychopathological symptoms (low Total Symptom Scores of the SCL-90-R) displayed high capacity for cooperation, good social skills, few inappropriate assertiveness behaviors, and low levels of impulsiveness, overconfidence, and jealousy-withdrawal.

\section{Relations between Psychopathological Symptoms and Personality Traits}

The Pearson correlation coefficients obtained from the analysis of the relations between psychopathological symptoms and personality traits are presented in Tables 2 and 3.

As can be seen in the above tables, the global examination of the results obtained reveals negative correlations between emotional stability and all the psychopathological symptoms explored with the SCL-90-R (including the Total Symptom Score, the Global Severity Index, the Positive Symptom Total, and the Positive Symptom Distress Index presented in Table 3). The significant correlations are confirmed in all the subdimensions of emotional stability, with positive correlations between psychopathological symptoms and maladjustment, anxiety, and depression, and negative correlations with stress tolerance and self-concept. These results suggest that adolescents who score high in emotional stability have few psychopathological symptoms. Hence, emotional stability and mental health are positively related.

As seen in Tables 2 and 3, in the global analysis of mental openness, no significant relations with any of the psychopathological scales were observed. However, the analysis of the subdimensions of this trait shows significant negative correlations between the subdimension toleranceflexibility and various psychopathological scales (especially with obsessive-compulsive, depression, hostility, and paranoid ideation) as well as the Total Symptoms Score, the Global Severity Index, the Positive Symptom Total, and the Positive Symptom Distress Index). Significant negative correlations were also confirmed between the subdimension adaptation to change and various psychopathological scales (especially, depression, hostility, and paranoid ideation) and the Total Symptoms Score, the Global Severity Index, the Positive Symptom Total, and the Positive Symptom Distress Index. In the subdimensions disposition towards new tasks and interest in other cultures, no noteworthy correlations with psychopathology were found.

The data from Tables 2 and 3 also reveal negative correlations between sociability, globally analyzed, and all 
the psychopathological symptoms. The significant correlations are confirmed in all the subdimensions of sociability: social intelligence, social integration, and teamwork. The only exception is the absence of relation between somatization and social intelligence. These data suggest that sociable adolescents have few psychopathological symptoms. Hence, sociability and mental health are positively related.

With regard to responsibility, the same results were observed as for emotional stability and sociability. The data in Tables 2 and 3 display significant negative correlations between responsibility and psychopathological symptoms in all the SCL-90-R scales, including the 4 indexes employed herein. The significant correlations are confirmed in all the trait subdimensions: self-demandingness, dynamism, and tenacity. The only exceptions refer to the lack of a correlation between tenacity and somatization, as well as the absence of significant correlations between dynamism and various symptoms (anxiety, paranoid ideation, psychoticism, and additional melancholic depression). These results suggest that adolescents with high scores in responsibility have few psychopathological symptoms in the scales evaluated. Hence, responsibility and mental health are also positively related.

\section{Predictor Variables of Psychopathological Symptoms}

In order to explore the variables that predict high scores in psychopathological symptoms (Total Symptom Score of the SCL-90-R), step-wise linear multiple regression analysis was performed, the results of which are presented in Table 4.

As can be observed, of the series of variables that predict psychopathological symptoms, four were statistically significant: jealousy-withdrawal $(\beta=.45)$, impulsiveness $(\beta=.17)$, social integration $(\beta=-.17)$, and self-concept $(\beta$ $=-.13)$. The standardized regression coefficients $(\beta)$ indicated that all the variables have some influence on psychopathological symptoms. As can be seen in the values of the adjusted determination coefficients, the predictor variables accounted for a considerable percentage of variance of psychopathological symptoms (42, 47, 45, and $49 \%$, respectively). The explanatory power of these variables is medium-high, as altogether they explain $49 \%$ of the variance.

\section{Discussion}

This study had two goals: the first goal was to analyze the relations of various psychopathological symptoms with adolescents' cooperativeness, social skills with four important personality dimensions. The second goal of the study was to identify possible predictors of psychopathological symptoms.

Of the relations between psychopathology and socialization, the results obtained in this study have shown that adolescents with many cooperative behaviors experienced few psychopathological symptoms, also reflected in their low scores on the Total Symptom Scores, the Global Severity Indexes, and the Positive Symptom Totals of the SCL-90-R. Therefore, the first hypothesis, which posited a significant negative relation between psychopathological symptoms and the capacity for cooperation, is confirmed.

Moreover, the results also confirm the negative correlations of psychopathological symptoms with social skills and the positive correlations with inappropriate assertiveness, impulsiveness, overconfidence, and jealousywithdrawal. This indicates that adolescents with few psychopathological symptoms have good social skills, few inappropriate assertiveness behaviors, and low levels of impulsiveness, jealousy-withdrawal, and overconfidence. The data confirm the second hypothesis, which proposed negative relations between psychopathological symptoms and social skills, and positive relations with inappropriate assertiveness, overconfidence, and jealousy-withdrawal.

Regarding the relations between psychopathological symptoms and various personality traits, the results show that adolescents with high emotional stability had few psychopathological symptoms in all the psychopathology scales of the SCL-90-R. Therefore, emotional stability and mental health are positively related, which ratifies the third hypothesis that posited negative relations between psychopathological symptoms and emotional stability.

No negative relations were found between psychopathological symptoms and mental openness, which leads to the rejection of the fourth hypothesis. However, the results confirm the significant negative correlations between psychopathology, sociability, and responsibility, indicating that sociable and responsible adolescents (scoring high in all three sociability dimensions) have few psychopathological

Table 4

Linear Multiple Regression Analysis for Predictor Variables of Psychopathological Symptoms

\begin{tabular}{llclr}
\hline Test / Predictor Variable & $R^{2}$ & Corrected $R^{2}$ & $\beta$ & $T$ \\
\hline MESSY / Jealousy-Withdrawal & .42 & .42 & .45 & $8.23 * * *$ \\
MESSY / Impulsiveness & .48 & .47 & .17 & $3.53 * * *$ \\
TPT / Social integration & .45 & .45 & -.17 & $-3.73 * * *$ \\
TPT / Self-concept & .49 & .49 & -.13 & $-2.76 * *$ \\
\hline
\end{tabular}

$* p<.05 . * * p<.01 . * * * p<.001$. 
symptoms. Therefore, sociability and responsibility are related to mental health, thus confirming the fifth and sixth hypothesis, which posited negative relations between these variables and psychopathological symptoms.

Lastly, the results of the regression analysis suggest that high scores in jealousy-withdrawal and impulsiveness, as measured by the MESSY, and low scores in social integration and self-concept, as measured by the TPT, are predictors of psychopathology (high scores in the Total Symptom Score of the SCL-90-R). This partially ratifies the seventh hypothesis, which stated that low levels of sociability would predict psychopathological symptoms.

The results obtained in this investigation point in the same direction as studies that found positive relations between mental health and self-concept/self-esteem (Erol et al., 2002; Fan \& Fu, 2001; Montt \& Chavez, 1996; Watson, 1998), as well as works that have emphasized the importance of social integration for mental health (Wilmoth \& Chen, 2003), pointing to difficulties in social relations as predictors of psychopathological symptoms (Richter, 1999).

This study also confirms the results of other works that have found negative relations between psychopathological symptoms and self-concept (Dowd, 2002; Garrick et al., 1988), and sociability (Watten et al., 1997), as well as investigations that found no relations between somatization and cooperation (Watten et al.). However, these results are not in accordance with the results of the study of Norman (2002), who found no relations between somatization and stress tolerance. The use of different assessment instruments to measure stress tolerance might explain this disparity. The negative relations between obsession-compulsion and selfconcept/self-esteem are also confirmed (Biby, 1998; Bohne et al., 2002), as well as between interpersonal sensitivity and self-esteem (Fan \& Fu, 2001; Jackson \& Cochran, 1991; Kim, 2003).

Along the lines of other investigations (Alfeld \& Sigelman, 1998; Biby, 1998; Bohne et al., 2002; Erkolahti et al., 2003; Fan \& Fu, 2001; Hoffmann et al., 2003; Kim, 2003; Sakamoto et al., 2002; Valentine, 2001), a negative correlation between depression and self-concept/self-esteem was found in this work and a positive correlation between depression and trait-anxiety (Bromberger \& Matthews, 1996). This is in accordance with a recent study of Ramos and Wilmoth (2003) that shows that social integration decreases depressive symptoms. Ratifying other investigations, negative relations between self-concept/self-esteem and anxiety (Bohne et al; Fickova, 1999; Garaigordobil et al., 2003; Newbegin \& Owens, 1996; Yang, 2002), hostilityaggressiveness (Allison, 2000; Marsh et al., 2001; O'Moore \& Kirkham, 2001; Rigby \& Slee, 1993; Rozenblatt, 2002), paranoid ideation (Ellett et al., 2003; Martin \& Penn, 2001), and psychoticism (Fan \& Fu, 2001) were also found.

As limitations of the study, the following should be noted: (a) The data analyzed are of a correlational nature, so they contribute little to the causal relation that may exist among the variables. Quasi-experimental investigation methodology is suggested as more adequate for the analysis of this aspect. (b) The high correlations found between psychopathological symptoms of the SCL-90-R and the Anxiety, Depression, Emotional Stability scales of the TPT, or the Jealousy-Withdrawal scales of the MESSY may be tautological. This is a topic that has been extensively debated within the framework of relations between personality and psychopathology, so that prudence is called for when interpreting the data; (c) The cross-sectional nature of the study may have conditioned the results of the predictive analysis.

Evidently, there are many factors (biological, psychological, family, interpersonal, etc.) to be taken into account in the prevention and treatment of psychopathology in adolescents. However, the results of this investigation have implications for the prevention of psychopathological disorders, and they provide support for the claims that psychological intervention programs that enhance children's socio-emotional development and socialization (cooperation, social skills, social intelligence, social integration, friendly relations, etc.) and promote the development of adaptive personality traits (emotional expression, control of emotions and impulses, high self-concept, stress tolerance, adaptation to change, self-demandingness, dynamism, tenacity, etc.) may prevent the development of psychopathological problems.

\section{References}

Alfeld, L.C., \& Sigelman, C.K. (1998). Sex differences in selfconcept and symptoms of depression during the transition to college. Journal of Youth and Adolescence, 27, 219-244.

Allison, M. (2000). Shame, guilt, and the belief in the legitimacy of aggression in aggressive adolescent girls. Dissertation Abstracts International: Section B: The Sciences and Engineering, 61 (3-B), 1622.

Biby, E.L. (1998). The relation between body dysmorphic disorder and depression, self-esteem, somatization, and obsessivecompulsive disorder. Journal of Clinical Psychology, 54, 489499.

Bohne, A., Keuthen, N.J., Wilhelm, S., Deckersback, T., \& Jenike, M.A. (2002). Prevalence of symptoms of body dysmorphic disorder and its correlates: A cross-cultural comparison. Psychosomatics: Journal of Consultation Liasion Psychiatry, 43, 486-490.

Bromberger, J.T., \& Matthews, K.A. (1996). A longitudinal study of the effects of pessimism, trait anxiety, and life stress on depressive symptoms in middle-aged women. Psychology and Aging, 11, 207-213.

Chang, E.C., \& D’Zurilla, T.J. (1996). Irrational beliefs as predictors of anxiety and depression in a college population. Personality and Individual Differences, 20, 215-219. 
Corral, S., Pamos, A., Pereña, J., \& Seisdedos, N. (2002). TPT. Test de Personalidad de TEA. Madrid: TEA.

Derogatis, L.R., \& Cleary, P.A. (1977). Confirmation of the dimensional structure of the SCL-90: A study in construct validation. Journal of Clinical Psychology, 33, 981-989.

Derogatis, L.R., Rickels, K., \& Rock, A.F. (1976). The SCL-90 and the MMPI: A step in the validation of a new self-report scale. British Journal of Psychiatry, 128, 280-289.

Derogatis, L.R. (1983). SCL-R: Administration, scoring and procedures manual for the $R$ (evised) version. Towson, MD: Clinical Psychometric Research. (Spanish adaptation: González de Rivera, J.L., De las Cuevas, C., Rodríguez Abuín, M., \& Rodríguez Pulido, F. (2002). SCL-90-R, Symptom Checklist 90 Revised, adaptación española. Madrid: TEA).

Dowd, S.A. (2002). Internalizing symptoms in adolescents: Assessment and relationship to self-concept. Dissertation Abstract International Section B: The Sciences and Engineering, 62 (8-B), 3796.

Ellett, L., Lopes, B., \& Chadwick, P. (2003). Paranoia in a nonclinical population of college students. Journal of Nervous and Mental Disease, 191, 425-430.

Erkolahti, R., Ilonen, T., Saarijarvi, S., \& Terho, P. (2003). Selfimage and depressive symptoms among adolescents in a nonclinical sample. Nordic Journal of Psychiatry, 57, 447-451.

Erol, A., Toprak, G., \& Yazici, F. (2002). Predicting factors of eating disorders and general psychological symptoms in female college students. Turk Psikiyatri Dergisi, 13, 48-57.

Fan, F., \& Fu, J. (2001). Self-concept and mental health of college students. Chinese Mental Health Journal, 15, 76-77.

Fickova, E. (1999). Personality dimensions and self-esteem indicators relationships. Studia Psychologica, 41, 323-328.

Garaigordobil, M., Cruz, S., \& Pérez, J.I. (2003). Análisis correlacional y predictivo del autoconcepto con otros factores conductuales, cognitivos y emocionales de la personalidad durante la adolescencia. Estudios de Psicología, 24, 113-134.

Garrick, T., Ostrov, E., \& Offer, D. (1988). Physical symptoms and self-image in a group of normal adolescents. Psychosomatics, 29, 73-80.

Giardinelli, L., Paionni, A., Zucchi, T., Viviani, B., \& Cabras, P.L. (1999). Differenze di genere e spettro ansioso-depressivo: la sensitivita interpersonale come fattore di rischio. / Gender differences and anxiety-depression spectrum: The interpersonal sensitivity as risk factor. Minerva Psichiatrica, 40, 55-60.

Godoy, A., Gavino, A., Martorell, M.C., \& Silva, F. (1993). Escala de Asertividad. In M. Forns \& M.T. Anguera (Eds.), Contribuciones recientes a la evaluación psicológica (pp. 247264). Barcelona: PPU.

González de Rivera, J.L., De la Hoz, J.L., Rodríguez Abuín, M., \& Monterrey, A.L. (1999). Disfunción témporo-mandibular y psicopatología: Un estudio comparativo con la población general y con pacientes psiquiátricos ambulatorios. Análisis de Psiquiatría, 15, 91-95.

González de Rivera, J.L., De las Cuevas, C., Rodríguez Abuín, M., \& Rodríguez Pulido, F. (2002). SCL-90-R, Symptom Checklist 90 Revised, adaptación española. Madrid: TEA.
Inderbitzen, H.M., \& Foster, S.L. (1992). The Teenage Inventory of Social Skills: Development, reliability and validity. Psychological Assessment, 4, 451-459.

Hoffmann, J.P., Baldwin, S.A., \& Cerbone, F.G. (2003). Onset of major depressive disorder among adolescents. Journal of the American Academy of Child and Adolescent Psychiatry, 42, 217-224.

Jackson, J., \& Cochran, S.D. (1991). Loneliness and psychological distress. Journal of Psychology, 125, 257-262.

Jin, S., \& Zhang, J. (1998). The effects of physical and psychological well-being on suicidal ideation. Journal of Clinical Psychology, 54, 401-413.

Kim, Y.H. (2003). Correlation of mental health problems with psychological constructs in adolescence: Final results from a 2year study. International Journal of Nursing Studies, 40, 115-124.

Lee, DY., Hallberg, E.T., Slemon, A.G., \& Haase, R.F. (1985). An Assertiveness Scale for Adolescents. Journal of Clinical Psychology, 41, 51-57.

Malouff, J., Thorsteinsson, E., \& Schutte, N. (2005). The relationship between the Five-Factor model of personality and symptoms of clinical disorders: A meta-analysis. Journal of Psychopathology and Behavioral Assessment, 27, 101-114.

Marsh, H.W., Parada, R.H., Yeung, A.S., \& Healey, J. (2001). Aggressive school troublemakers and victims: A longitudinal model examining the pivotal role of self-concept. Journal of Educational Psychology, 93, 411-419.

Martin, J.A., \& Penn, D.L. (2001). Social cognition and subclinical paranoid ideation. British Journal of Clinical Psychology, 40, 261-265.

Matson, J.L., Rotatori, A.F., \& Helsel, W.J. (1983). Development of a rating scale to measure social skills in children: The Matson Evaluation of Social Skills with Youngsters (MESSY). Behavior Research Therapy, 21, 335-340. (Spanish adaptation: Trianes, M. V., Blanca, M. J., Muñoz, A., García, B., CardelleElawar M., \& Infante L. (2002). Relaciones entre evaluadores de la competencia social en preadolescentes: Profesores, iguales y autoinformes. Anales de Psicología, 18, 197-214.)

Méndez, F.X., Hidalgo, M.D., \& Inglés, C.J. (2002). The Matson Evaluation of Social Skills with youngsters. European Journal of Psychological Assessment, 18, 30-42.

Montt, M.E., \& Chavez, F.U. (1996). Autoestima y salud mental en los adolescentes. Salud Mental, 19, 30-35.

Newbegin, I., \& Owens, A. (1996). Self-esteem and anxiety in secondary school achievement. Journal of Social Behavior and Personality, 11, 521-530.

Norman, M. (2002). Resilience and its role in the perception of stress and psychosomatic symptoms in African Americans. Dissertation Abstracts International: Section B: The Sciences and Engineering, 62 (9-B), 4229.

O'Moore, M, \& Kirkham, C. (2001). Self-esteem and its relationship to bullying behaviour. Aggressive Behavior, 27, 269-283.

Ramos, M., \& Wilmoth, J. (2003). Social relationships and depressive symptoms among older adults in southern Brazil. Journals of Gerontology: Series B: Psychological Sciences and Social Sciences, 58B, S253-S261. 
Richter, S.S. (1999). Social relationships and psychological symptoms in a treatment-seeking university student sample. Dissertation Abstracts International: Section B: The Sciences and Engineering, 60 (1-B), 0374.

Rigby, K., Cox, I., \& Black, G. (1997). Cooperativeness and bully/victim problem among Australian schoolchildren. The Journal of Social Psychology, 137, 357-368.

Rigby, K., \& Slee, P.T. (1993). Dimensions of interpersonal relation among Australian children and implications for psychological well-being. Journal of Social Psychology, 133, 33-42.

Roland, E. (2002). Aggression, depression and bullying others. Aggressive Behavior, 28, 198-206.

Rozenblatt, S. (2002). In defense of the self: The relationship of self-esteem and narcissism to aggressive behavior. Dissertation Abstracts International: Section B: The Sciences and Engineering, 63 (4-B), 2072.

Sakamoto, S., Tomoda, A., \& Kijima, N. (2002). Association of self-preoccupation and self-reported duration and severity of depressive episodes. Psychological Reports, 90, 861-868.

Takakura, M., \& Sakihara, S. (2001). Psychosocial correlates of depressive symptoms among Japanese high school students. Journal of Adolescent Health, 28, 82-89.
Valentine, I.S. (2001). The relationship between depression, self-esteem, trauma, and psychopathy in understanding conduct disordered adolescents. Dissertation Abstracts International Section B: The Sciences and Engineering, 61 (10-B), 5585.

Watson, D.C. (1998). The relationship of self-esteem, locus of control, and dimensional models to personality disorders. Journal of Social Behavior and Personality, 13, 399-420.

Watten, R.G., Vassend, O., Myhrer, T., \& Syversen, J.L. (1997). Personality factors and somatic symptoms. European Journal of Personality, 11, 57-68.

Wilmoth, J.M., \& Chen, P.C. (2003). Immigrant status, living arrangements, and depressive symptoms among middle-aged and older adults. Journals of Gerontology: Series B: Psychological Sciences and Social Sciences, 58 B, 305-313.

Yang, D. (2002). Depression, anxiety, and self-concept of middle school students. Chinese Mental Health Journal, 16, 633635 .

Received May 18, 2006

Review received June 21, 2006

Accepted July 10, 2006 